\title{
Comparative assessment on in vitro antioxidant activities of ethanol extracts of Averrhoa bilimbi, Gymnema sylvestre and Capsicum frutescens
}

\author{
Md. Mominur Rahman, Md. Razibul Habib', Md. Anayet Hasan², Mohammad Al Amin², Ayan Saha², \\ Adnan Mannan²
}

Department of Pharmacy, International Islamic University Chittagong, Chittagong, Bangladesh, ${ }^{1}$ Superintendent of Drugs, Directorate General of Drug Administration, Dhaka, ${ }^{2}$ Department of Genetic Engineering and Biotechnology, Faculty of Biological Sciences, University of Chittagong, Chittagong-4331, Bangladesh

Submitted: 03-06-2013

Revised: 21-07-2013

Published: 12-12-2013

A B S T R A C T

Background: Averrhoa bilimbi, Gymnema sylvestre and Capsicum frutescens are medicinal plants commonly used as traditional medicine for the treatment of various diseases. The present study was designed to investigate the antioxidant activities of Ethanolic extract of A. bilimbi, G. sylvestre and $C$. frutescens. Materials and Methods: The antioxidant activity of the extracts were evaluated using total phenolic and flavonoid contents, ferric reducing power and the free radical scavenging activity against 1,1-diphenyl-2-picrylhydrazyl (DPPH). Results: Total phenolic and flavonoid contents were higher in G. sy/vestre $(53.63636 \pm 0.454545 \mathrm{mg} / \mathrm{g}$ gallic acid equivalent) and $C$. frutescens (26.66667 $\pm 2.081666 \mathrm{mg} / \mathrm{g}$ quercetin equivalent) respectively. Reducing power of the crude ethanol extracts increased with the concentrations of the extracts and all the extracts showed moderate free radical scavenging activity against DPPH. The plant extract displayed moderate phenolic and flavonoid contents compared to gallic acid and quercetin equivalent respectively, whereas also exhibited significant scavenging of DPPH radical and reducing power compared with ascorbic acid as standard. Conclusion: Our study suggests that $G$. sylvestre has significant antioxidant activity. The antioxidant compound of this plant might be a therapeutic candidate against oxidative stress related diseases. Different sub-fraction of $A$. bilimbi and $C$. frutescens should be studied further to assess the effect. Further study is necessary for isolation and characterization of the active antioxidant agents for better treatment.

Key words: Antioxidant, G. sylvestre, ethanolic extract, free radical, oxidative stress

\section{INTRODUCTION}

Antioxidants in a biological system have several functions, which include protection from oxidative damage and participating in the major signaling pathways of the cells. One of the major actions of antioxidants in cells is to prevent damage caused by the action of reactive oxygen species (ROS). ROS include the superoxide anion $\left(\mathrm{O}_{2}\right)$, hydrogen peroxide, nitric acid radicals and free radicals such as the hydroxyl radical are generated in living organisms

\section{Address for correspondence:}

Dr. Adnan Mannan, Department of Genetic Engineering and

Biotechnology, Faculty of Biological Sciences, University of

Chittagong, Chittagong - 4331, Bangladesh.

E-mail: adnan.mannan@cu.ac.bd during excessive metabolism. ${ }^{[1-3]}$ These molecules are highly reactive and unstable and they cause extensive oxidative cell damage by chain reactions leading to cancer promoting mutation or cell death, age related degenerative diseases and a wide range of human diseases. In order to prevent or reduce this damage, all cells invariably contain antioxidants. ${ }^{[4-6]}$ ROS such as superoxide, hydroxyl and peroxyl radicals are formed in human cells by exogenousl and endogenous factors. ${ }^{[7]}$

Several synthetic antioxidants such as butylated hydroxytoluene, butylated hydroxyanisol and tert-butylhydroquinone are commercially available and currently in use. However, use of such antioxidants is now constrained due to their side effects. It has been revealed that they stimulate the development of cancerous cells 
in rats. These findings have strengthened the efforts for the development of alternate antioxidants from natural sources. $^{[8]}$

Moreover, antioxidants from natural origin increase the shelf-life of foods. ${ }^{[9]}$ Consequently, consumption of antioxidants and accumulation of antioxidant in food materials protect the body against various agents. Many researchers have reported various types of antioxidants in different kinds of higher plants. ${ }^{[10,11]}$ In this regards many antioxidants have already been isolated from different kinds of natural origin, such as oilseeds, vegetables, cereal crops, spices and herbs. ${ }^{[12,13]}$

G. sylvestre commonly known as Gurmar is a traditional herb used for medicinal purpose. It is distributed in the tropical forests of southern and central India, Bangladesh and Sri Lanka. ${ }^{[14]}$ It is used as a treatment for diabetes for near two millennia. ${ }^{[15]}$

Averrhoa bilimbi also called Bilimbi are found throughout the Indonesia, Philippines, Bangladesh, Sri Lanka, Myanmar (Burma) and Malaysia. It is also common in other Southeast Asian countries. Bilimbi has been used in traditional medicine to control obesity and diabetes mellitus. ${ }^{[16]}$ It also possesses anti-hyperlipidemic properties. ${ }^{[17]}$

Capsicum frutescens is an aromatic plant, which is spread throughout the tropical and subtropical regions. It is not only an edible vegetable, but also used in folk remedies to inhibit the growth of gastric pathogen Helicobacter pylori, ${ }^{[18]}$ inhibit platelet aggregation ${ }^{[19]}$ and also used as anti-diabetic, GI stimulant, mildly diuretic. ${ }^{[20,21]}$

Until date, there is no detail information in the scientific literature on the antioxidant properties of aqueous extract of Gymnema sylvestre, A. bilimbi and C. frutescens. Therefore, the aim of this study is to investigate whether herbal preparations (aqueous extract) from G. sylvestre, $A$. bilimbi and $C$. frutescens possess antioxidant activity or not, which may be beneficiary for diseases caused by ROS. In addition, relationship between antioxidant activities, 1,1-diphenyl-2-picrylhydrazyl (DPPH) radical scavenging activity, reducing power, total phenolic content and flavonoid content were also analyzed.

\section{MATERIALS AND METHODS}

\section{Sample collection}

C. frutescens, G. sylvestre and A. bilimbi were collected from Bangladesh Council of Scientific and Industrial Research laboratories and brought directly to our laboratory. Samples were picked up and washed through tap water first then with distilled water to remove dirt particles. Samples were cut into small pieces and then dried first in sunlight followed by electric dryer at a temperature of $60^{\circ} \mathrm{C}-70^{\circ} \mathrm{C}$. The samples were pulverized by mechanical grinder. Later on powder sample was kept into separate airtight container to preserve.

\section{Extract preparation}

C. frutescens, $G$. sylvestre and A. bilimbi was then subjected to ethanol extraction. Each extraction processes repeated twice. After that extracts were subjected to filtration in a cotton filter and filtrates were collected. Using a hot water bath at $60^{\circ} \mathrm{C}$ solvent from the extracts evaporated and kept in vacuum container for $72 \mathrm{~h}$ then they were concentrated using a rotary evaporator.

\section{Procurement of chemicals and drugs}

We purchased DPPH (trichloroacetic acid) and ferric chloride from Sigma Chemical Company of USA, Ascorbic acid from SD Fine Chem. Ltd. of India and ammonium molybdate from Merck, Germany.

\section{Total phenolic compound}

Amount of phenolic content of ethanol extracts were determined by widely used Folin-Ciocalteau method. ${ }^{[22]}$ Aliquot of samples were mixed with $\mathrm{Na}_{2} \mathrm{CO}_{3}$. At room temperature in dark absorbance of all aliquots measured at $760 \mathrm{~nm}$ wave length twice for each sample at the same concentration. Total phenolic content was expressed as $\mathrm{mg}$ gallic acid equivalent (GAE)/g of extract.

\section{Total flavonoid content determination}

Kumaran and Karunakaran method we used to determine the flavonoid content ${ }^{[23]}$ and quercetin was used as standard. The $1 \mathrm{mg}$ extract was mixed with $1 \mathrm{ml}$ of aluminium trichloride in ethanol $(20 \mathrm{mg} / \mathrm{ml})$ and then one drop of acetic acid added. The mixture was then diluted up to $25 \mathrm{ml}$ with ethanol and 40 min later, the absorbance measured at a wave length of $415 \mathrm{~nm}$. Measurement of blank samples and standard quercetin was done under the same condition.

\section{DPPH radical scavenging activity}

The DPPH radical scavenging activity of our extracts was performed by using standard protocols. ${ }^{[24]}$ This assay is based on the measurement of the ability of antioxidants to scavenge the stable radical DPPH. The extract was diluted in methanol to make $10,50,100,500 \mu \mathrm{g} / \mathrm{mL}$ dilutions. $2 \mathrm{~mm}$ of each dilution was mixed with $1 \mathrm{~mL}$ of DPPH solution $(0.2 \mathrm{mM} / \mathrm{mL}$ in methanol $)$ and mixed thoroughly. The mixture was incubated in the dark at $20^{\circ} \mathrm{C}$ for $40 \mathrm{~min}$. Free radical DPPH is reduced to corresponding hydrazine when it reacts with hydrogen donors. ${ }^{[25]}$ The decrease of solution absorbance due to proton donating activity of 
components of each extract was determined at $517 \mathrm{~nm}$. Lower absorbance of mixture indicates higher free radical scavenging capability. ${ }^{[26]}$ Absorbance of DPPH activity was measured at $517 \mathrm{~nm}$ using ultraviolet-vis spectrophotometer with methanol as blank. Vitamin C was used as the positive control. Finally, the result was measured at $\mathrm{IC}_{50}$ value and then the percentage of scavenging of DPPH by the extracts was calculated as formula:

Percentage DPPH radical scavenging $=\left(\left[A_{c}-A_{t}\right] / A_{c}\right) \times 100$.

Here, Ac is the absorbance of the control (DPPH) and $A_{\mathrm{t}}$ is the absorbance of the test samples.

\section{Reducing power}

The reducing power of our sample extracts was determined by the method of Oyaizu. ${ }^{[27]}$ Different concentration of sample extract $(10,50,100,500 \mu \mathrm{g})$ in $1 \mathrm{ml}$ of distilled water was mixed with phosphate buffer $(2.5 \mathrm{ml}, 0.2 \mathrm{M}, \mathrm{pH}$ 6.6) and potassium ferricyanide $\left.\mathrm{K}_{3} \mathrm{Fe}(\mathrm{CN})_{6}\right](2.5 \mathrm{ml}, 1 \%)$. The mixture was incubated at $50^{\circ} \mathrm{C}$ for $20 \mathrm{~min}$. Centrifugation of the mixture was done at $3000 \mathrm{rpm}$ for $10 \mathrm{~min}$ after adding little amount of $(2.5 \mathrm{ml})$ of trichloro acetic acid $(10 \%)$. The upper layer of the solution was mixed with distilled water and $\mathrm{FeCl}_{3}(0.5 \mathrm{ml}, 0.1 \%)$ and then reading of the absorbance was taken at $700 \mathrm{~nm}$. Here, ascorbic acid was reference standard and the blank solution had phosphate buffer in it.

\section{RESULTS}

\section{TPC}

Total Phenolic content followed by Folin-Ciocalteau method is showed in Table 1. Phenolic content of A. bilimbi, $G$. sylvestre and C. frutescens is $38.78788 \pm 0.946212$, $53.63636 \pm 0.454545$ and $33.0303 \pm 2.049659 \mathrm{mg} / \mathrm{g} \mathrm{GAE}$ respectively after replicating the process thrice [Table 1].

\section{TFC}

Using Kumaran and Karunakaran method and quercetin as standard TFC was determined in the present study. It was found that A. bilimbi, G. sylvestre and $C$. frutescens has $1.666667 \pm 0.872334,18.66667 \pm 7.767453$ and $26.66667 \pm 2.081666 \mathrm{mg} / \mathrm{g}$ quercetin equivalents. The result we got here is statistically significant $(P<0.05)$ [Table 1]. This step was replicated thrice.

\section{DPPH scavenging activity}

The DPPH radical scavenging activity of $A$. bilimbi, G. sylvestre and C. frutescens is shown in Table 2. With the increase of the concentration of the extract, DPPH activity was found to increase. The inhibitory capacity of the plant extract was compared with the ascorbic acid standard. The DPPH activity in extracts from A. bilimbi, G. sylvestre and $C$. frutescens extracts was $635.066 \pm 8.4102,303.8639$

\begin{tabular}{lcc} 
Table 1: Total phenolic and flavonoid content \\
\hline & $\begin{array}{c}\text { Total phenolic } \\
\text { content }\end{array}$ & $\begin{array}{c}\text { Total flavonoid } \\
\text { content }\end{array}$ \\
\hline A. bilimbi & $38.78788 \pm 0.946212^{*}$ & $1.666667 \pm 0.872334^{*}$ \\
G. sylvestre & $53.63636 \pm 0.454545^{*}$ & $18.66667 \pm 7.767453^{*}$ \\
C. frutescens & $33.0303 \pm 2.049659^{*}$ & $26.66667 \pm 2.081666^{*}$ \\
\hline
\end{tabular}

*Denotes $P<0.05$. A. bilimbi=Averrhoa bilimbi; G. Sylvestre $=$ Gymnema sylvestre; $C$. frutescens=Capsicum frutescens

\begin{tabular}{|c|c|c|}
\hline & $I_{50}$ value & $P$ value \\
\hline A. bilimbi & $635.066 \pm 8.4102$ & $>0.05$ \\
\hline G. Sylvestre & $303.8639 \pm 0.971$ & $<0.05$ \\
\hline C. frutescens & $423.26 \pm 107.2199$ & $<0.05$ \\
\hline Ascorbic acid & $98.56 \pm 0.754$ & $<0.05$ \\
\hline
\end{tabular}

\pm 0.971 and $423.066 \pm 8.4102$ respectively; whereas the standard has a value of $98.56 \pm 0.754 \mu \mathrm{g} / \mathrm{ml}$. Figure 1 shows the percentage of scavenging activity for different concentration of extracts and compared with the vitamin C standard. From the Figure $\mathrm{IC}_{50}$ value was measured which is shown in Table 2 with $P$ value. When the values were compared for three extracts. The most effective radical scavenging activity was shown by $G$. sylvestre, while the least effective was the extract of $A$. bilimbi. $C$. frutescens also showed significant scavenging activity.

\section{Reducing power}

By using the $\mathrm{K}_{3} \mathrm{Fe}(\mathrm{CN}){ }_{6}$ reduction method the reducing capacity of the plant extracts was identified in comparison with ascorbic acid, which demonstrated in Figure 2. The reducing power of the extracts was moderately strong while increasing concentration shows a gradual increase in reducing power.

\section{DISCUSSION}

Plant produces a large number of phenolic compounds with several biological activities. ${ }^{[28]}$ Phenolics such as phenolic acids, flavonoids and tannins are considered to be the major contributor to the antioxidant ability of plants. These antioxidants of the plant also possess diverse biological activities, such as anti-carcinogenic, free radical scavenger, anti-atherosclerotic and anti-inflammatory, activities. These all activities are related to their antioxidant capacity. ${ }^{[29]}$ Phenolic compounds contribute evidently to antioxidative action and they constitute the major class of natural antioxidants present in plants; ${ }^{[30]}$ therefore, it is necessary to calculate total phenolic content in plant species. In present study, using Folin-Ciocalteau method we found different response from three different samples in various concentration for each which were quantitively 


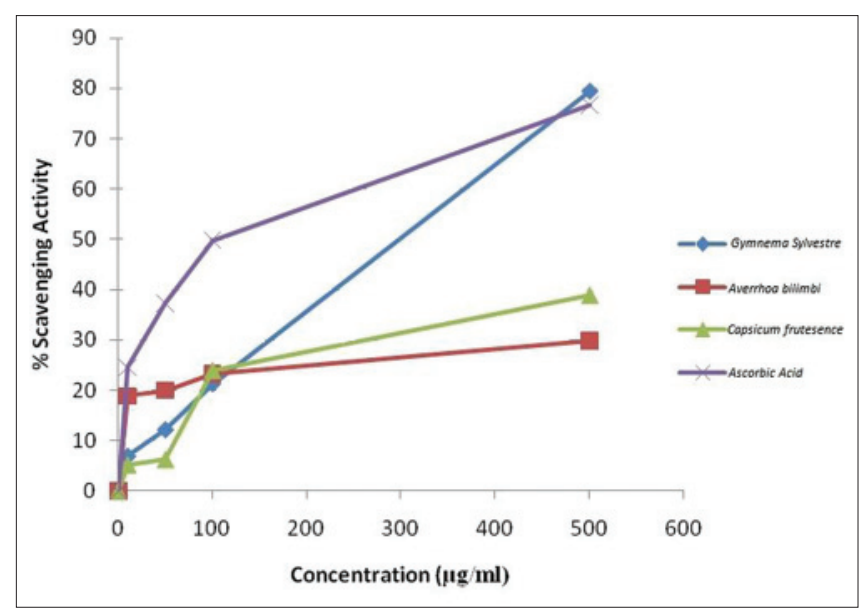

Figure 1: Scavenging activity

expressed as $\mathrm{mg} \mathrm{GAE} / \mathrm{g}$ of extract. Here, sodium carbonate produces blue color of phosphormolybdicphosphor tungstic phenol complex. Thus, most concentrated blue color contains highest total phenolic content. ${ }^{[31]}$ According to results [Table 1] G. sylvestre has the highest amount of phenolic content than $C$. frutescens and $A$. bilimbi. Present studies indicate the presence of polyphenolic compound in G. sylvestre, C. frutescens and A. bilimbi.

The quantitative estimation of flavonoid content of C. frutescens, G. sylvestre and A. bilimbi shows that they are also rich with this compound. Thus our result of flavonoid content determination test shows [Table 1] that C. frutescens is rich in flavonoid than G. sylvestre, A. bilimbi but all are with a considerable amount. Flavonoids are the naturally occurring compounds in plants and thought to have positive influences on human health. Several studies on flavonoids derivatives showed that they have a wide range of anti-inflammatory antibacterial, antiviral, anti-inflammatory, antiviral, anticancer and anti-allergic activities. ${ }^{[32,33]}$ It is well-established that plant flavonoids are highly effective, free radical scavenging and antioxidants. Flavonoids are used for the prevention and cure of different diseases. ${ }^{[34]}$ Recent interest in these substances has been stimulated by the potential health benefits arising from their antioxidant activities and free radical scavenging capacities in coronary heart disease and cancer. ${ }^{[35]}$

Phenolic compounds are commonly found in both edible and inedible plants and they have been noticed to have wider biological effects, including antioxidant activity. It has been reported that compounds such as phenolics, flavonoids, which contain hydroxils, are responsible for the radical scavenging activity of most plant. ${ }^{[3]}$ The result of DPPH scavenging activity of ethanolic extracts [Table 2] indicates they are fairly significant scavenger of free radical when compared with standard ascorbic acid measured at $\mathrm{IC}_{50}$ value. $\mathrm{IC}_{50}$ value is a parameter able to inhibit $50 \%$ of the DPPH. $\mathrm{IC}_{50}$ value of

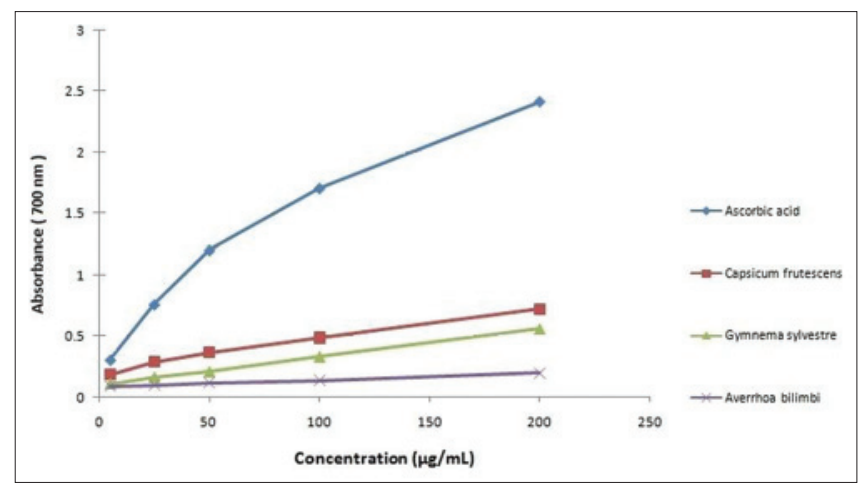

Figure 2: Reducing power

extracts was compared to the $\mathrm{IC}_{50}$ of the standard obtained by the same procedure. In comparative analysis, $G$. sylvestre is the most active and significant $(P<0.05)$ scavenger than other two, whereas $A$. bilimbi extract exhibited the lowest activity among three samples of different species [Table 2]. Extracts show a gradual increase in activity with increase of concentration. DPPH is a commonly used substrate for rapid assessment of antioxidant activity because of its stability and simplicity of the assay. ${ }^{[3]]}$ DPPH scavenging capacity of antioxidants is due to hydrogen donating ability. DPPH is stable nitrogen centered free radical, which produces violet color in ethanol solution ${ }^{[37}$ and accepts an electron or hydrogen radical to become more stable diamagnetic molecule. When a DPPH solution is mixed with a hydrogen atom donor, a stable non-radical form of DPPH is found with simultaneous change in color from violet to pale yellow. ${ }^{[38]}$ This assay gives reliable information about the antioxidant activity of the tested compounds. ${ }^{[36,39,40]} \mathrm{It}$ is possible to correlate the reduction in the number of DPPH molecules with the number hydroxyl groups. ${ }^{[4]]}$

Reducing power is a good pointer of antioxidant activity. The plant having high reducing power generally reported to carry high antioxidant potential too. ${ }^{[34]}$ Reduction of $\mathrm{Fe}(\mathrm{III})$ by electron-donating activity of the compounds reflects the antioxidant mechanism of the compound. In this experiment, Ferric ions are reduced to ferrous with the color of the reaction mixture changes from yellow to bluish green. The ferric reducing power activity of $C$. frutescens, G. sylvestre and $A$. bilimbi extract with compared to ascorbic acid are reported in Figure 2. Extract exhibited dose dependent reducing power potential. However, the efficacy was found to be lower than that of ascorbic acid.

This study indicates that G. sylvestre has a significant antioxidant activity and the ethanolic extract of $C$. frutescens has moderate antioxidant activity. These plants can be further assessed for active antioxidant compound and future therapeutic potential. 


\section{REFERENCES}

1. Ragupathi R, Kannan R, Arumugam R, Anantharaman P. In vitro antioxidant activities of ethanol extract from Enhalus acoroides (L.F.) Royle. Asian Pac J Trop Med 2010;3:898-901.

2. Aruoma IO, Cuppette SL. Antioxidant Methodology: In vivo and in vitro Concepts. Illinois: AOAS Press; 1997.

3. Devi GK, Manivannan K, Thirumaran G, Rajathi FA, Anantharaman P. In vitro antioxidant activities of selected seaweeds from Southeast coast of India. Asian Pac J Trop Med 2011;4:205-11.

4. Aruoma OI. Antioxidant actions of plant foods: Use of oxidative DNA damage as a tool for studying antioxidant efficacy. Free Radic Res 1999;30:419-27.

5. Prakash D, Upadhyay G, Singh BN, Singh HB. Antioxidant and free radical-scavenging activities of seed and agri-waste of some varieties of soyebean (glycine max). Food Chem 2007;104:783-90.

6. Borek C. Molecular mechanisms in cancer induction and prevention. Environ Health Perspect 1993;101 Suppl 3:237-45.

7. Reaven PD, Witztum JL. Oxidized low density lipoproteins in atherogenesis: Role of dietary modification. Annu Rev Nutr 1996;16:51-71.

8. Huang HL, Wang BG. Antioxidant capacity and lipophilic content of seaweeds collected from the Qingdao coastline. J Agric Food Chem 2004;52:4993-7.

9. Schwarz K, Bertelsen G, Nissen LR, Gardnu PT, Heinonen NI, Hopia A. Investigation of plant extracts for the protection of processes foods against lipid oxidation: Comparison of antioxidant assays based on radical scavenging, lipid oxidation and analysis of the principal antioxidant compounds. Eur Food Res Technol 2001;212:319-28.

10. Larson RA. The antioxidants of higher plants. Phytochemistry 1988;27:969-78.

11. Shon MY, Kim TH, Sung NJ. Antioxidants and free radical scavenging activity of Phellinus baumii (phellius of hymenochaetaceae) extracts. Food Chem 2003;82:593-7.

12. Tsao R, Deng Z. Separation procedures for naturally occurring antioxidant phytochemicals. J Chromatogr B Analyt Technol Biomed Life Sci 2004;812:85-99.

13. Liyana-Pathirana CM, Shahidi F. Importance of insoluble-bound phenolics to antioxidant properties of wheat. J Agric Food Chem 2006;54:1256-64.

14. Al-Romaiyan A, Liu B, Asare-Anane H, Maity CR, Chatterjee SK, Koley N, et al. A novel Gymnema sylvestre extract stimulates insulin secretion from human islets in vivo and in vitro. Phytother Res 2010;24:1370-6.

15. Yeh GY, Eisenberg DM, Kaptchuk TJ, Phillips RS. Systematic review of herbs and dietary supplements for glycemic control in diabetes. Diabetes Care 2003;26:1277-94.

16. Pari L, Saravanan G. Antidiabetic effect of Cogent db, a herbal drug in alloxan-induced diabetes mellitus. Comp Biochem Physiol C Toxicol Pharmacol 2002;131:19-25.

17. Krishnaveni M, Mirunalini S, Karthiswaran K, Dhamodharan G. Antidiabetic and antihyperlipidemic properties of Phyllanthus emblica Linn. (Euphorbiaceae) on streptozotocin induced diabetic rats. Pak J Nutr 2010;9:43-51.

18. Saeed S, Tariq P. Effects of some seasonal vegetables and fruits on the growth of bacteria. Pak J Biol Sci 2006;9:1547-51.

19. Puett D, Wasserman BK, Ford JD, Cunningham LW. Collagen-mediated platelet aggregation. Effects of collagen modification involving the protein and carbohydrate moieties. J Clin Invest 1973;52:2495-506.

20. Vinayaka KS, Kekuda PT, Nandini KC, Rakshitha MN, Martis R, Shruthi $\mathrm{J}$, et al. Potent insecticidal activity of fruits and leaves of
Capsicum frutescens (L.) var. longa (Solanaceae). Der Pharm Lett 2010;2:172-6.

21. Barik R, Jain S, Qwatra D, Joshi A, Tripathi GS, Goyal R. Antidiabetic activity of aqueous root extract of Ichnocarpus frutescens in streptozotocin-nicotinamide induced type-II diabetes in rats. Indian J Pharmacol 2008;40:19-22.

22. Singleton VL, Rossi JA. Colorimetry of total phenolics with phosphormolybdic phosphotungstic acid reagents. Am J Enolvitic 1965;16:144-58.

23. Kumaran A, Karunakaran AJ. In vitro antioxidant activities of methanol extracts of five Phyllanthus species from India. LwtFood Sci and Technol 2007;40:344-52.

24. Priya CL, Kumar G, Karthik L, Rao KV. Antioxidant activity of Achyranthes aspera Linn stem extracts. Pharmacologyonline 2010;2:228-37.

25. Ganga RB, Madhu KP, Vijaya RA. Investigation of antioxidant and anti-inflammatory activity of leaves of Dalbergia paniculata (Roxb). Asian Pac J Trop Med 2012;5:455-8.

26. Chowdhury AR, Qureshi MZ, Raza SA, William J, Arshad M. Quantitative Determination of Antioxidant Potential of Artemisia persica. Vol. 19. University of Bucharest, Romania: ARS Docendi Publishing House; 2010. p. 23-30.

27. Oyaizu M. Studies on product of browning reaction prepared from glucoseamine. Jpn J Nutr 1986;44:307-15.

28. Michalak A. Phenolic compounds and their antioxidant activity in plants growing under heavy metal stress. Pol J Environ Stud 2006;15:523-30.

29. Chung KT, Wong TY, Wei Cl, Huang YW, Lin Y. Tannins and human health: A review. Crit Rev Food Sci Nutr 1998;38:421-64.

30. Awika JM, Rooney LW, Wu X, Prior RL, Cisneros-Zevallos L. Screening methods to measure antioxidant activity of sorghum (Sorghum bicolor) and sorghum products. J Agric Food Chem 2003;51:6657-62.

31. Verzelloni E, Tagliazucchi D, Conte A. Relationship between the antioxidant properties and the phenolic and flavonsoid content in traditional balsamic vinegar. Food Chem 2007;105:564-71.

32. Di Carlo G, Mascolo N, Izzo AA, Capasso F. Flavonoids: Old and new aspects of a class of natural therapeutic drugs. Life Sci 1999;65:337-53.

33. Montoro P, BracaA, Pizza C, De Tommasi N. Structure-antioxidant activity relationships of flavonoids isolated from different plant species. Food Chem 2005;92:349-55.

34. Atanassova M, Georgieva S, Ivancheva K. Total phenolic and total flavonoid contents, antioxidant capacity and biological contaminants in medicinal herbs. Journal of the University of Chemical Technology and Matallurgy 2011;46:81-8.

35. Yao LH, Jiang YM, Shi J, Tomás-Barberán FA, Datta $N$, Singanusong $\mathrm{R}$, et al. Flavonoids in food and their health benefits. Plant Foods Hum Nutr 2004;59:113-22.

36. Jothy SL, Zuraini Z, Sasidharan S. Phytochemicals screening, DPPH free radical scavenging and xanthine oxidase inhibitory activities of Cassia fistula seeds extract. J Med Plants Res 2011;5:1941-7.

37. Nanjo F, Goto K, Seto R, Suzuki M, Sakai M, Hara Y. Scavenging effects of tea catechins and their derivatives on 1,1-diphenyl-2-picrylhydrazyl radical. Free Radic Biol Med 1996;21:895-902.

38. Milardović S, Iveković D, Grabarić BS. A novel amperometric method for antioxidant activity determination using DPPH free radical. Bioelectrochemistry 2006;68:175-80.

39. Khanduja KL, Bhardwaj A. Stable free radical scavenging and antiperoxidative properties of resveratrol compared in vitro with some other bioflavonoids. Indian J Biochem Biophys 2003;40:416-22.

40. Yamaguchi T, Takamura H, Matoba T, Terao J. HPLC method 
for evaluation of the free radical-scavenging activity of foods by using 1,1-diphenyl-2-picrylhydrazyl. Biosci Biotechnol Biochem 1998;62:1201-4.

41. Umamaheswari $\mathrm{M}$, Chatterjee TK. In vitro antioxidant activities of the fractions of Coccinia grandis L. leaf extract. Afr J Tradit Complement Altern Med 2007;5:61-73.
Cite this article as: Rahman MM, Habib MR, Hasan MA, Amin MA, Saha A, Mannan A. Comparative assessment on in vitro antioxidant activities of ethanol extracts of Averrhoa bilimbi, Gymnema sylvestre and Capsicum frutescens. Phcog Res 2014;6:36-41.

Source of Support: Nil, Conflict of Interest: None declared. 